\title{
Ownership and Usage of Mobile Devices Among Ophthalmology Residents and Attending Physicians: Identifying the Generation Gap
}

This article was published in the following Dove Press journal: Advances in Medical Education and Practice

Adi Mohammed

Al Owaifeer (D) ${ }^{1,2}$

Abdulaziz Al Taisan'

Bader Alqahtani ${ }^{3}$

Khalid Alburayk ${ }^{4}$

Majed Alsubaie ${ }^{5}$

Saad H Alenezi $\mathbb{D}^{6}$

'Faculty of Ophthalmology, College of Medicine, King Faisal University, Al-Ahsa, Saudi Arabia; ${ }^{2}$ King Khaled Eye Specialist Hospital, Riyadh, Saudi Arabia;

${ }^{3}$ Department of Ophthalmology, King Abdulaziz Medical City, Jeddah, Saudi Arabia; ${ }^{4}$ College of Medicine, Prince Sattam bin Abdulaziz University, Al-Kharj, Saudi Arabia; ${ }^{5}$ Dhahran Eye Specialist Hospital, Dhahran, Saudi Arabia; ${ }^{6}$ Department of Ophthalmology, College of Medicine, Majmaah University, Majmaah, Saudi Arabia
Correspondence: Adi Mohammed Al Owaifeer

Faculty of Ophthalmology, College of Medicine, King Faisal University, P.O. Box 400, Al-Ahsa 31982, Saudi Arabia

Tel +966135808573

Fax +966135800820

Email aalowaifeer@kfu.edu.sa
Background: Ophthalmology residents strongly rely on digital technology in training. This characteristic may not be shared by their teachers, attending physicians. Therefore, the aim of this study was to describe the ownership and usage of mobile devices among Saudi ophthalmology residents and their attending physicians and to compare ownership and usage patterns between both groups.

Methods: A survey was conducted to determine the rates of ownership of mobile devices and the patterns of usage among Saudi ophthalmology residents and their attending physicians. The survey was sent to 305 eligible participants.

Results: The overall response rate was $81 \%$. The mean age of residents and attendings was 27.4 and 48.6 years, respectively. The ownership of mobile phones was higher among attendings $(1.21 \pm 0.4$ vs $1.36 \pm 0.5, \mathrm{p}=0.02)$, whereas the ownership of tablets was higher among residents $(1 \pm 0.6$ vs $0.7 \pm 0.6, p=0.01)$. Residents utilized mobile devices to access online educational resources more frequently compared to attendings. A statistically significant difference between residents and attendings was reported in the utilization of wikis ( $91 \%$ vs $46 \%$ ), e-books ( $90 \%$ vs $54 \%$ ), file sharing sites ( $84 \%$ vs $52 \%$ ), and vodcasts $(78 \%$ vs $58 \%$ ). Both groups also differed with regards to reasons of utilization. While residents most commonly used mobile devices to answer clinical questions on demand (87\%) and to acquire basic knowledge $(84 \%)$, the main reasons of utilization cited by attendings were to look up controversial issues $(77 \%)$ and to connect with peers $(72 \%)$.

Conclusion: The two studied groups differ from each other in the type of devices owned, reasons for usage, and frequency of utilization. The difference in behavior between educators and their students can lead to a generation gap that halts the progress of residents' training. Keywords: educational resources, medical education, health communication, digital technology

\section{Background}

Digital technology has become an integral part of practice in the healthcare sector. As a result, mobile devices (laptops, tablets, and smartphones) are currently widely distributed among healthcare professionals. ${ }^{1}$ The majority of training doctors today are members of the millennial generation (also known as Generation Y), which were born in the 1980s and 1990s. A significant characteristic of this generation is that they strongly rely on digital technology to obtain and share medical information. ${ }^{2,3}$

A major advantage of digital technology in medical education is the availability of online educational resources (OERs). Internet-based education was shown to be 
as effective as traditional methods in educating healthcare professionals. $^{4}$ Moreover, studies have shown that Millennial learners in the medical field are inclined towards the incorporation of OERs into their learning process. ${ }^{5,6}$ This trend has been further emphasized with the introduction of smartphones into the technology market. A high level of smartphone ownership and medical education App usage is observed among medical students and junior doctors. ${ }^{7}$

The majority of teachers involved in the training of junior doctors are members of Generation X, which were born in the period between 1960 and 1980, or older. This generation has specific qualities, attitudes, and learning preferences. A major characteristic is that they are less inclined towards embracing digital technology when compared to their students. ${ }^{8}$ This may introduce a generation gap that may halt the learning process of future doctors.

The primary objective of this study was to describe the ownership and usage of mobile devices among Saudi ophthalmology residents and their attending physicians. A secondary objective was to compare ownership and usage patterns between residents and their attendings.

\section{Methods}

This is a cross-sectional study based on an electronic selfadministered questionnaire. The study protocol was conducted in accordance with the ethical standards set by the World Medical Association Declaration of Helsinki. ${ }^{9}$ The questionnaire was developed based on a review of the pertinent literature. ${ }^{8,10,11}$ Then, a focus group drafted the initial survey that was divided into the following domains: personal information, ownership of mobile devices, reasons for usage, and utilization of OERs. A pilot survey was sent to 20 healthcare professionals, not included in the study, and their feedback was used to refine the survey for better readability and understanding.

The final survey was delivered through a secure online portal (SoGoSurvey). Invitations to participate were sent to all residents and attendings currently involved in all ophthalmology training programs in Saudi Arabia. In order to ensure a high response rate and minimize nonresponse bias, a modified Dillman method ${ }^{12}$ was used. First, the survey was sent electronically to all the target population. Then, a reminder is sent to non-responders after two weeks and four weeks. Finally, those that still did not respond were approached either personally or through a phone call. Responses were collected during the period between December 2017 and October 2018.
All responses were anonymous and the completion of the survey was voluntary. An entry to a draw for an iPad was used as an incentive to motivate participants.

Data were exported from SoGoSurvey for analysis. Incomplete surveys were not included in the study. Descriptive statistics were used to present frequencies, means, SD, and percentages. To compare between both groups $t$-test was used for continuous variables, and chisquare test was used for categorical variables. Statistical significance was set at a $\mathrm{P}$ value of $<0.05$. Statistical analysis was conducted using R (RStudio version 1.1.463 Mac, RStudio Inc., Boston, MA).

\section{Results}

Out of 305 eligible participants, 248 completed the survey, creating a response rate of $81 \%$. The residents' response rate was $87 \%(146 / 167)$ and the response rate among attendings was $74 \%(102 / 138)$. Five participants did not complete all the components of the survey, and therefore, were not included in the analysis. A flow chart of eligibility and study participation is shown in Figure 1.

The mean age of residents was 27 years while the mean age of attendings was 48 years. Males comprised the majority (76\%) of attendings while male residents were $58 \%$. About half of the study participants (53\%) were from Riyadh residency training program. Detailed demographics are shown in Table 1.

Details on the ownership of mobile devices among the respondents are shown in Table 2. The overall mean

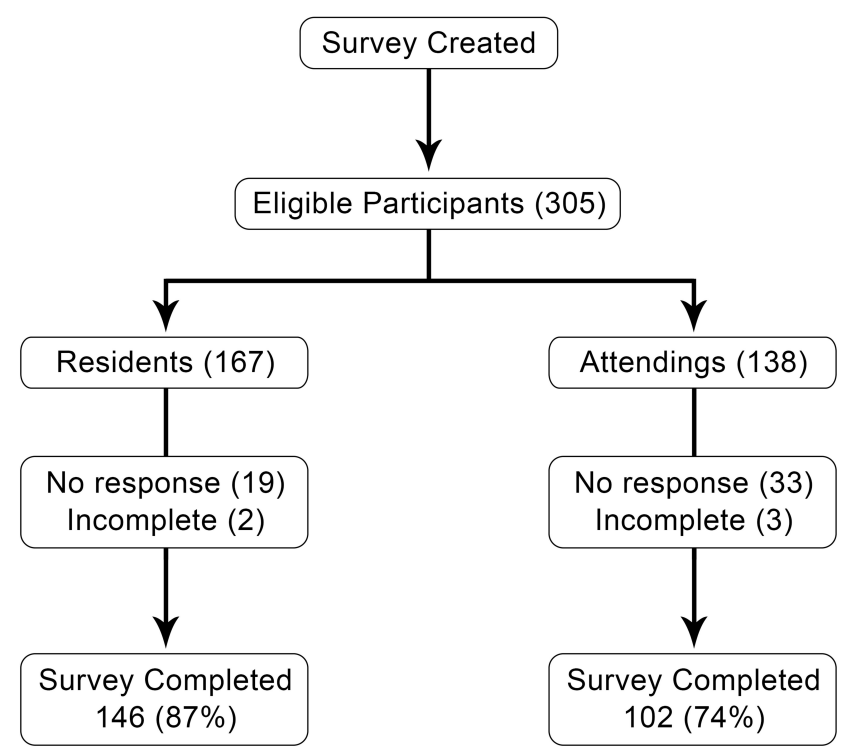

Figure I Flow chart of eligibility, participation, and survey completion. 
Table I Demographic Details of Survey Respondents

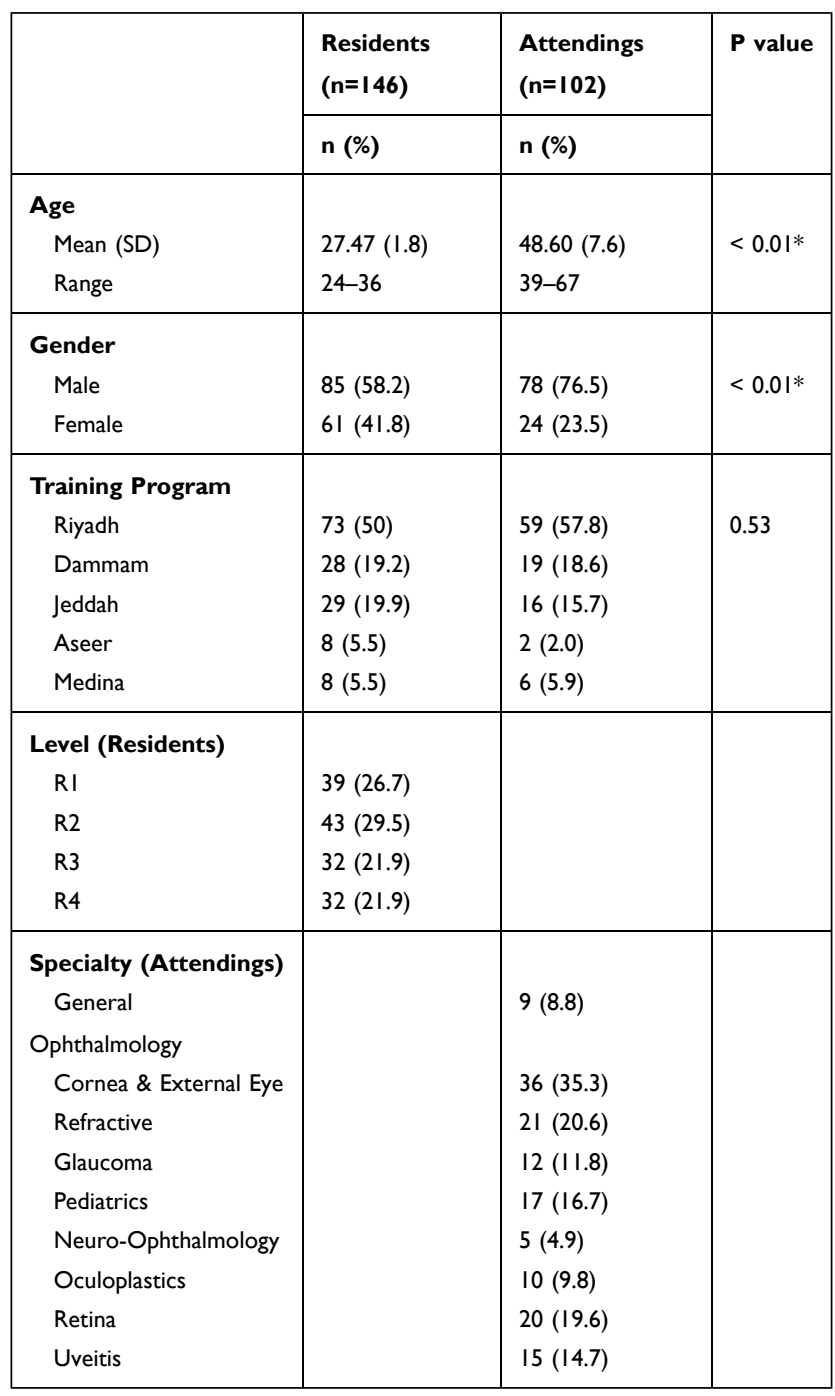

Note: *Statistically significant $(\mathrm{P}$ value $<0.05)$.

number of mobile devices owned was 3.29. In both groups, the ownership of mobile phones was the highest, followed by laptops, and then tablets. Upon comparing both groups, residents had a higher number of tablets $(\mathrm{p}<0.01)$, while attendings had more mobile phones $(\mathrm{p}=0.02)$.

When asked about their utilization of mobile devices during the last month, residents used their devices to access OERs more frequently compared to their attendings. The most commonly utilized resources by residents are online wikis (91\%), e-books (90\%), and file sharing sites $(84 \%)$. A statistically significant difference between residents and attendings was reported in the utilization of wikis ( $91 \%$ vs $46 \%$ ), e-books ( $90 \%$ vs $54 \%$ ), file sharing sites ( $84 \%$ vs $52 \%$ ), and vodcasts ( $78 \%$ vs $58 \%$ ) (Figure 2 , Supplementary Table a).
Figure 3 (Supplementary Table b) shows the reasons for using mobile devices among survey respondents. The main reasons for usage reported by residents were: answering clinical questions on demand (87\%), basic knowledge (84\%), and connecting with peers (74\%). On the other hand, attendings utilized mobile devices to look up controversial issues $(77 \%)$, connect with peers $(72 \%)$, and answer clinical questions on demand (65\%).

\section{Discussion}

The current study demonstrates that respondents of our survey, both residents and attendings, are adopters of digital technology with a mean number of owned devices reaching three per individual. These results are in concordance with previously published reports both locally ${ }^{13}$ and internationally ${ }^{14}$ that have also shown a high level of ownership of mobile devices among healthcare professionals.

There is a notable difference between both groups with regards to the type of mobile device owned. For example, $84 \%$ of residents have at least one tablet compared to $39 \%$ of attendings that do not have one. Previous reports have also shown an increasing prevalence and frequency of usage of tablet computers among junior physicians. ${ }^{15}$ From the standpoint of millennial doctors, tablets are considered a valuable utility that complements their learning experience.

Looking into the utilization of mobile devices, several differences exist between both groups. The frequency of residents accessing online wikis and reading books in an electronic format (91\% and $90 \%)$ is near to double that of attendings (46\% and 54\%). This reflects the difference in learning habits between the two generations as attendings are probably still attached to physical textbooks as a major source of acquiring information.

The utilization of file sharing sites was higher among residents $(84 \%)$ compared to their attendings (52\%). In recent years, the popularity of file hosting cloud-based applications increased among healthcare professionals as a method of storing, indexing, and sharing clinical content. ${ }^{16}$ Our findings suggest that the penetration of such technology into members of generation $\mathrm{X}$ is less compared to their students.

The survey also showed a difference in utilizing mobile devices to access video content (78\% vs 58\%). The use of video in medical education has increased exponentially over the last years as an effective tool to complement traditional lectures ${ }^{17}$ as well as teach procedural skills. ${ }^{18}$ The difference in the uptake of video between the two 
Table 2 Ownership of Mobile Devices Among Survey Respondents

\begin{tabular}{|c|c|c|c|}
\hline & $\begin{array}{l}\text { Residents } \\
(n=\mid 46)\end{array}$ & $\begin{array}{l}\text { Attendings } \\
(n=102)\end{array}$ & $p$ value \\
\hline & n (\%) & n (\%) & \\
\hline \multicolumn{4}{|l|}{ Phones } \\
\hline One & II 8 (80.8) & $67(65.7)$ & \\
\hline Two & $25(17.1)$ & $33(32.4)$ & \\
\hline Three & $3(2.1)$ & $2(2.0)$ & \\
\hline Mean (SD) & I.2I (0.46) & $1.36(0.52)$ & $0.02 *$ \\
\hline \multicolumn{4}{|l|}{ Tablets } \\
\hline None & $23(15.8)$ & $40(39.2)$ & \\
\hline One & $101(69.2)$ & $53(52.0)$ & \\
\hline Two & $21(14.4)$ & $8(7.8)$ & \\
\hline Three & I (0.7) & I (I.0) & \\
\hline Mean (SD) & I $(0.58)$ & $0.7(0.65)$ & $<0.0 I^{*}$ \\
\hline \multicolumn{4}{|l|}{ Laptops } \\
\hline None & $3(2.1)$ & $6(5.9)$ & \\
\hline One & $123(84.2)$ & $74(72.5)$ & \\
\hline Two & $19(13.0)$ & $22(21.6)$ & \\
\hline Three & I (0.7) & $0(0.0)$ & \\
\hline Mean (SD) & I.I2(0.4) & I.I5 (0.5) & 0.58 \\
\hline
\end{tabular}

Note: *statistically significant $(\mathrm{P}$ value $<0.05)$.

studied groups is of great importance. If teachers do not utilize video content as much they will be less inclined to suggest suitable content for their students.

Mobile devices, particularly phones and tablets, provide clinicians with the luxury of acquiring on-demand answers to clinical questions arising at point of care. Our survey showed that $87 \%$ of residents utilize their mobile devices for such purpose. A valid point of criticism of this method is the unknown quality and reliability of such information. A survey published by Duran-Nelson et $\mathrm{al}^{19}$ reported a high reliance of medical residents on Google to look up information at point of care. Despite being quick and easy to access, Google shows search results from various web pages regardless of their quality. Therefore, residents

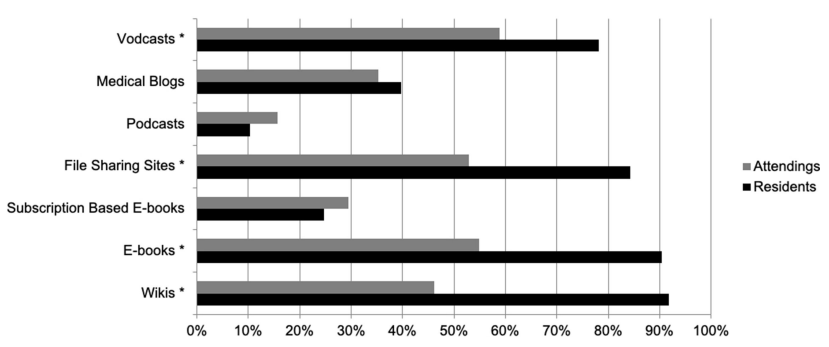

Figure 2 Monthly (or more) utilization of OERs among survey respondents. *P $<0.05$, Pearson's Chi-squared test with Yates' continuity correction.

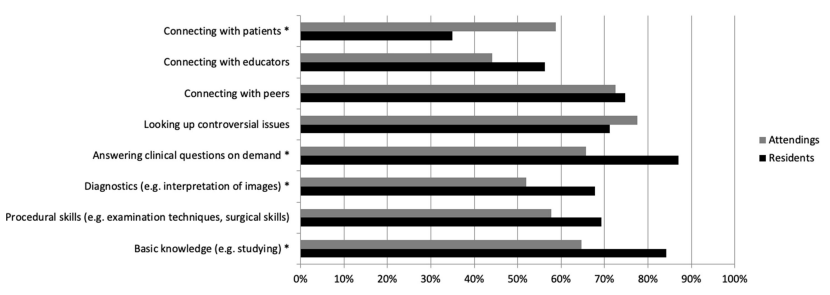

Figure 3 Reasons for use of mobile devices among survey respondents. $* \mathrm{P}<0.05$, Pearson's Chi-squared test with Yates' continuity correction.

should have appropriate information management skills to be able to scrutinize online information for credibility.

Our study has several limitations. First, since the survey was electronic it was subject to sampling bias as those individuals that utilize mobile devices more frequently were more likely to participate, however, we tried to minimize such an effect by inviting non-participants through a phone call. Second, the survey was also subject to nonresponse bias, however, many measures were introduced to limit it such as a defined target population, availability of contact information for all subjects, and the implementation of a modified Dillman method. Subsequently, we had a high overall response rate $(81 \%)$. Finally, the majority of our questions were closed-ended. We deliberately formulated the survey in this manner as we assumed that this will increase completion rate and reduce recall bias.

\section{Conclusions}

The current study demonstrates a high level of ownership of mobile devices among both residents and their attendings. These devices are used in various aspects of medical education and clinical practice. The two studied groups differ from each other in the type of devices owned, reasons for usage, and frequency of utilization. Compared to their attendings, a higher number of residents own a tablet computer, furthermore, residents utilize OERs more frequently. The difference in behavior between educators and their students can lead to a generation gap that halts the progress of residents' training. Future research is needed to clearly define the implication of such a gap and discuss potential solutions to bridge it.

\section{Abbreviation}

OERs, online educational resources.

\section{Data Sharing Statement}

The data that support the findings of the current study are available from the corresponding author upon reasonable request. 


\section{Ethics Approval and Consent to Participate}

Approval of the institutional review board at King Faisal University was not required as per guidelines that do not require approval for an online survey. Participants indicated consent to participate at the beginning of the questionnaire after reading a full description about the study. Clicking on a "I agree to participate" button was required to commence the questionnaire. As an incentive, all participants were entered in a draw for the chance to win a tablet computer.

\section{Author Contributions}

All authors made a significant contribution to the work reported, whether that is in the conception, study design, execution, acquisition of data, analysis and interpretation, or in all these areas; took part in drafting, revising or critically reviewing the article; gave final approval of the version to be published; have agreed on the journal to which the article has been submitted; and agree to be accountable for all aspects of the work.

\section{Funding}

There is no funding to report.

\section{Disclosure}

The authors report no conflicts of interest in this work.

\section{References}

1. Ozdalga E, Ozdalga A, Ahuja N. The smartphone in medicine: a review of current and potential use among physicians and students. J Med Internet Res. 2012;14(5):e128. doi:10.2196/jmir.1994

2. Weiler A. Information-seeking behavior in generation $\mathrm{Y}$ students: motivation, critical thinking, and learning theory. $J$ Acad Librariansh. 2005;31(1):46-53. doi:10.1016/j.acalib.2004.09.009

3. Hamm MP, Chisholm A, Shulhan J, et al. Social media use by health care professionals and trainees: a scoping review. Acad Med. 2013;88 (9):1376-1383. doi:10.1097/ACM.0b013e31829eb91c

4. Cook DA, Levinson AJ, Garside S, Dupras DM, Erwin PJ, Montori VM. Internet-based learning in the health professions: a meta-analysis. JAMA. 2008;300(10):1181-1196. doi:10.1001/jama.300.10.1181
5. Barry DS, Marzouk F, Chulak-Oglu K, Bennett D, Tierney P, O'Keeffe GW. Anatomy education for the YouTube generation. Anat Sci Educ. 2016;9(1):90-96. doi:10.1002/ase.1550

6. Berkowitz SJ, Kung JW, Eisenberg RL, Donohoe K, Tsai LL, Slanetz PJ. Resident iPad use: has it really changed the game? $J \mathrm{Am}$ Coll Radiol. 2014;11(2):180-184. doi:10.1016/j.jacr.2013.04.017

7. Payne KFB, Wharrad H, Watts K. Smartphone and medical related App use among medical students and junior doctors in the United Kingdom (UK): a regional survey. BMC Med Inform Decis Mak. 2012;12(1):1. doi:10.1186/1472-6947-12-121

8. Purdy E, Thoma B, Bednarczyk J, Migneault D, Sherbino J. The use of free online educational resources by canadian emergency medicine residents and program directors. Can J Emerg Med. 2015;17 (2):101-106. doi:10.1017/cem.2014.73

9. Review C, Communication S, Principles G. World Medical Association; World Medical Association declaration of Helsinki ethical principles for medical research involving human subjects. J Int Bioéthique. 2004;15(1):124. doi:10.3917/jib.151.0124.

10. Masika MM, Omondi GB, Natembeya DS, Mugane EM, Bosire KO, Kibwage IO. Use of mobile learning technology among final year medical students in Kenya. Pan Afr Med J. 2015;21:1-12. doi:10.11604/pamj.2015.21.127.6185

11. Somal K, Lam W, Tam E. Computer and internet use by ophthalmologists and trainees in an academic centre. Can J Ophthalmol. 2009;44 (3):265-268. doi:10.3129/i09-057

12. Hoddinott SN, Bass MJ. The dillman total design survey method. Can Fam Physician. 1986;32(November):2366-2368.

13. Jamal A, Temsah M-H, Khan SA, Al-Eyadhy A, Koppel C, Chiang MF. Mobile phone use among medical residents: a cross-sectional multicenter survey in Saudi Arabia. JMIR mHealth uHealth. 2016;4(2):e61. doi:10.2196/mhealth.4904

14. Smart NJ. A survey of smartphone and tablet computer use by colorectal surgeons in the UK and Continental Europe. Color Dis. 2012;14 (9):e535-e538. doi:10.1111/j.1463-1318.2012.03161.x

15. Robinson R. Spectrum of tablet computer use by medical students and residents at an academic medical center. PeerJ. 2015;3:e1133. doi:10.7717/peerj.1133

16. Chan T, Sennik S, Zaki A, Trotter B. Studying with the cloud: the use of online Web-based resources to augment a traditional study group format. CJEM. 2015;17(2):192-195. doi:10.2310/8000.2014.141425

17. Tang F, Chen C, Zhu Y, et al. Comparison between flipped classroom and lecture-based classroom in ophthalmology clerkship. Med Educ Online. 2017;22(1):1395679. doi:10.1080/10872981.2017.1395679

18. Wang V, Cheng Y-T, Liu D. Improving education: just-in-time splinting video. Clin Teach. 2016;13(3):183-186. doi:10.1111/tct.12394

19. Duran-Nelson A, Gladding S, Beattie J, Nixon LJ. Should we Google it? Resource use by internal medicine residents for point-of-care clinical decision making. Acad Med. 2013;88(6):788-794. doi:10.1097/ACM.0b013e31828ffdb7

\section{Publish your work in this journal}

Advances in Medical Education and Practice is an international, peerreviewed, open access journal that aims to present and publish research on Medical Education covering medical, dental, nursing and allied health care professional education. The journal covers undergraduate education, postgraduate training and continuing medical education including emerging trends and innovative models linking education, research, and health care services. The manuscript management system is completely online and includes a very quick and fair peer-review system. Visit http://www.dovepress.com/testimonials.php to read real quotes from published authors. 